\title{
El modelo cooperativo y el nuevo enfoque del desarrollo territorial: elementos de convergencias y potenciales sinergias
}

\author{
Jesús María Gómez García \\ Profesor Titular de Economía Aplicada \\ Universidad de Valladolid
}

Sumario: I. Introducción. II. Los nuevos enfoques del desarrollo económico territorial. III. El modelo cooperativista y la economía social. IV. El cooperativismo y el enfoque del desarrollo territorial «desde abajo»: convergencias y potenciales sinergias. $V$. Las cooperativas agrarias y el desarrollo territorial rural en España. VI. Conclusiones. VII. Referencias bibliográficas.

Resumen: El nuevo enfoque del desarrollo territorial "desde abajo», basado en procesos de carácter endógeno y base local, se fundamenta en la participación de los agentes económicos y sociales en los procesos transformadores del territorio para asegurar mayor impacto económico y social. El cooperativismo supone un modelo con elevada capacidad para potenciar la actividad económica del territorio, generar empleo de calidad, favorecer la cultura emprendedora local e impulsar la mejora del nivel y la calidad de vida de la comunidad, fijando la población al territorio. Entre ambos enfoques existen convergencias y potenciales sinergias. Las cooperativas, en particular las agrarias, por su fuerte vinculación social y anclaje territorial, constituyen una forma empresarial clave para el desarrollo territorial en el medio rural.

Palabras clave: Desarrollo económico territorial, Desarrollo endógeno y local, Cooperativismo, Cooperativas agrarias.

Abstract: The new approach to territorial development «from below» based on endogenous processes and local dimension, is based upon the participation of economic and social agents in the transformation processes of the territory to ensure further economic and social impact. Cooperativism represents a model with high capacity to strengthen economic activity in the territory, generate quality jobs, promote local entrepreneurial culture and encourage the improvement of the level and quality of life of the community, setting the population into the territory. There are clear convergences and potential synergies between these two approaches. Coperatives, particularly the agrar- 
ian, due to their strong social links and territorial anchoring, are key corporate form for territorial development in rural areas.

Key words: Territorial economic development, Endogenous and local development, Cooperatives, Agrarian cooperatives. 


\section{Introducción}

El fenómeno del cooperativismo ha sido objeto de estudio desde diversas perspectivas disciplinarias. Así, desde el mundo jurídico se ha prestado particular atención a las sociedades cooperativas, no sólo porque son la única forma empresarial que tiene presencia a nivel constitucional ${ }^{1}$, en tanto que entidades que promocionan la socialización de los medios de producción y la participación de los trabajadores dentro de la empresa, sino también por el propio desarrollo que ha venido experimentando el ordenamiento jurídico que las regula en España².

Por su parte, desde el ámbito de la Ciencia Económica también se ha estudiado el fenómeno del cooperativismo prestando especial atención a las características del entorno empresarial que crea, a su capacidad económica para producir bienes y servicios y a la importancia que está adquiriendo en el marco del mercado globalizado, especialmente en el contexto de las economías en desarrollo. Y también desde una perspectiva sectorial, las cooperativas han sido objeto de interés investigador, y particularmente en el ámbito agrario, por tratarse de una forma concreta de manifestación del desarrollo empresarial que, de algún modo, trata de encontrar un equilibrio entre la actividad económica, la comunidad local y el territorio. Desde esta perspectiva, el papel de la economía social, y del cooperativismo en particular, ha llamado también la atención de los economistas en cuanto que entidades que interactúan en los procesos de desarrollo territorial, ya sea regional, rural o local. Y ello, tanto por la influencia de los valores y principios que otorgan especificidad al modelo cooperativo, que combina elementos de búsqueda de la eficiencia empresarial con la participación democrática, la cohesión social y el bienestar de la comunidad, como también por la estrecha vinculación que este tipo particular de empresas mantienen con el ámbito territorial en el que operan, promoviendo un denso entramado de relaciones con los diferentes agentes socioeconómicos que tienen relevancia territorial, lo que las convierte en entidades que refuerzan la cohesión a nivel económico, social y territorial.

1 Según el artículo 129.2 de la Constitución Española de 1978, «Los poderes públicos promoverán eficazmente las diversas formas de participación en la empresa y fomentarán, mediante una legislación adecuada, las sociedades cooperativas. También establecerán los medios que faciliten el acceso de los trabajadores a la propiedad de los medios de producción».

2 Junto con la Ley de Sociedades Cooperativas de España (Ley 27/1999 de 16 de julio), la gran mayoría de las Comunidades Autónomas españolas dispone de regulación propia. La última norma aprobada ha sido la Ley 6/2013, de 6 de noviembre, de Cooperativas de Cantabria (BOE n. ${ }^{\circ} 284$, de 27 de noviembre de 2013, pp. 94155-94244). 
Este trabajo se centra en analizar el modelo cooperativo y en poner en valor su papel en los procesos de desarrollo territorial, lo que adquiere especial relevancia en el contexto económico actual, caracterizado por profundos cambios en la dinámica de las relaciones comerciales en favor de una creciente globalización y unos mercados más competitivos, pero también por una situación marcada por las terribles consecuencias de una crisis económica y financiera de intensidad sin precedentes, que ha menoscabado los estándares sociales en Europa, elevando las tasas de paro y de pobreza, y que ha afectado desigualmente a las poblaciones y los territorios. En este sentido, se destacará la capacidad de las cooperativas para amortiguar los efectos negativos de la crisis, no sólo por haber resistido mejor que otras formas empresariales en términos de pérdida neta de empleo ${ }^{3}$, sino también por su papel positivo a la hora de preservar la cohesión económica y social.

Según datos de la Confederación Empresarial Española de Economía Social (CEPES) a comienzos del año 2014, el sector de cooperativo nacional englobaba 21.800 empresas, empleando a cerca de 280.000 personas. La tasa de paro en las cooperativas era casi 6 puntos inferior a la media nacional y el valor estimado de la producción cooperativa en términos del PIB nacional era del $6 \%$ en 2012. Por Comunidades Autónomas, en siete de ellas (País Vasco, Murcia, Navarra, Extremadura, Comunidad Valenciana, Andalucía, Castilla y León, y La Rioja) se superaba el promedio nacional, destacando el caso del País Vasco, en el que el sector cooperativo suponía algo más de la mitad del PIB regional para ese año ${ }^{4}$.

La idea central es que el modelo cooperativo, desarrollado en torno a unos valores y principios de identidad y que cristaliza en la forma empresarial de la sociedad cooperativa, presenta unas características organizativas, económicas y funcionales especialmente compatibles con los nuevos enfoques actuales aplicados para promover el desarrollo territorial. Y, paralelamente, también tratar de poner de manifiesto que estos nuevos enfoques incorporan en parte la filosofía cooperativista en tanto que representan, en esencia, una solución de naturaleza cooperativa, caracterizada por un alto grado de participación y compromiso

3 A escala europea, el empleo en las cooperativas cayó el 9\% entre 2008 y 2012, mientras que el empleo asalariado privado lo hizo el 19\%, más del doble (Monzón y Chaves, 2012: 93).

4 Elaboración propia a partir de datos de Contabilidad Regional de España, Base 2010 y las estadísticas de Economía Social del M. ${ }^{\circ}$ Ministerio de Empleo y Seguridad Social. 
entre los actores locales, a la hora de abordar el desarrollo económico de un territorio de forma integral y orientado también a mejorar el nivel y la calidad de vida de la población. Cabe, por tanto, pensar en la existencia de elementos de convergencia y de potenciales sinergias entre el cooperativismo y los nuevos enfoques del desarrollo territorial endógeno y local. En este sentido, las cooperativas pueden desempeñar no solo un papel de apoyo sino, en muchos casos, de liderazgo en las estrategias de desarrollo territorial debido a su fuerte anclaje local y a su gran permeabilidad con respecto a los deseos, necesidades y decisiones de la comunidad local.

De acuerdo con lo expuesto, tras esta introducción, se examinan los aspectos básicos que configuran el nuevo enfoque conceptual que se aplica en los procesos de desarrollo territorial, basados en las ideas de desarrollo "desde abajo» y la utilización de los recursos endógenos, propios de los modelos de desarrollo local y rural. A continuación, se analiza el modelo cooperativista en el ámbito de la economía social, con especial referencia a los valores y principios que rigen la identidad cooperativa moderna. Posteriormente, se señalan los diversos puntos de convergencia y las posibles sinergias entre el cooperativismo y el enfoque "desde abajo» que se aplica en el marco de las nuevas estrategias de desarrollo territorial. Y tras ello, se revisa el papel del cooperativismo agrario en el marco del desarrollo territorial rural en España y se hace una breve reseña de su relevancia cuantitativa. Por último, se incluye un apartado de conclusiones y otro final de referencias bibliográficas.

\section{Los nuevos enfoques del desarrollo económico territorial}

El desarrollo económico territorial es, en esencia, un proceso que tiene como finalidad el progreso de la comunidad vinculada a un ámbito espacial y cuyo objetivo último ha de ser procurar el bienestar económico y social de las personas que habitan en él; es decir, la mejora del nivel y la calidad de vida de la población. Hablar de desarrollo económico territorial es, en definitiva, hablar también de promoción del empleo y de actividad empresarial (emprendimiento) en un ámbito geográfico concreto, sea éste regional, rural o local, por ejemplo.

Durante el último tercio del pasado siglo tuvo lugar en el contexto de los países desarrollados una búsqueda de alternativas a los tradicionales modelos de desarrollo económico imperantes hasta entonces y basados, por lo general, en una visión de carácter agregado y en la importancia de la atracción de recursos financieros externos al terri- 
torio ${ }^{5}$. La causa fue su incapacidad para resolver los graves problemas que iban apareciendo, relacionados con la persistencia de un elevado desempleo, los desequilibrios observados en la distribución de la renta por zonas geográficas y la falta de flexibilidad de las estructuras productivas. En el origen de la necesidad de encontrar nuevas propuestas en las que fundamentar el sostenimiento y promoción del desarrollo económico territorial se encuentran los profundos efectos de la crisis económica de principios de los años setenta, que provocaron notables alteraciones en los ámbitos productivo, institucional y social de los países ${ }^{6}$.

En efecto, dentro del ámbito productivo, la crisis produjo una creciente incertidumbre económica, que se ha ido agudizando en las diversas crisis económicas y financieras que les han afectado. Se produjeron, asimismo, fuertes cambios en los mercados y en la competencia, con la intensificación del fenómeno de la globalización económica y el fortalecimiento de los procesos de deslocalización productiva entre territorios. Y también tuvo lugar un acelerado proceso de cambio tecnológico dentro y fuera de las empresas, resultado de los programas de innovación tecnológica y de la creciente utilización de las nuevas tecnologías de la información y la comunicación (TIC).

Por su parte, en el plano institucional y en el ámbito social también se observan importantes alteraciones en cuanto a la configuración tradicional existentes hasta entonces. Destacan, entre estos cambios, los procesos de descentralización política, reflejo de una creciente demanda de participación de la sociedad civil en la toma de decisiones económicas y sociales. Y también, desde mediados de los años ochenta, cambios en favor de la promoción económica y social de los recursos autóctonos (ya sean humanos, naturales, institucionales, sociales, culturales, etc.) presentes en el territorio, así como del papel de los propios agentes locales que operan en él, como unos aspectos que comienzan a adquirir una nueva dimensión dentro de los procesos tendentes al desarrollo económico regional y local.

Todos estos cambios condujeron, en suma, a una modificación sustancial en el enfoque conceptual a la hora de abordar los procesos de desarrollo económico territorial; de modo que, frente a las tradicionales teorías del desarrollo basadas en la necesidad de procurar una fuerte

5 VÁZQUEZ BARQUERO, A.: Las nuevas fuerzas del desarrollo, Editorial Antoni Bosch, Barcelona, 2005, 178 pp.

6 RODRÍGUEZ COHARD, J. C.: «Los procesos de desarrollo local: formas de organización e instrumentos». Ponencia en: I/ Seminario Práctico de Economía social «La economía social y el desarrollo local y regional». 2005. Valladolid. 
concentración de los esfuerzos económicos en ciertas áreas y de fomentar una intervención de agentes externos para lograr el desarrollo de una determinada área deprimida, cobran relevancia los enfoques alternativos que plantean la necesidad de aplicar patrones productivos más flexibles y de corte más descentralizado (regional, local, rural), basados en la valorización y el aprovechamiento de todos los recursos propios existentes, así como en la versatilidad de las PYMES y en la cultura cooperativa entre los agentes locales como vías eficaces para la generación de empleo y renta. Y, en suma, de utilizar su «potencial endógeno» como elemento clave de desarrollo económico y social7.

Bajo esta nueva perspectiva, los nuevos procesos de desarrollo territorial, regional y local, modifican progresivamente su orientación pasando de tener un enfoque «desde arriba» a otro "desde abajo», en el que el territorio y los agentes (privados y públicos) que integran la comunidad local adoptan un papel activo y directo en el proceso de desarrollo económico y social, tratando de aprovechar las posibles fortalezas internas y de promover la movilización de todos los recursos de valor existentes en la zona. De este modo, el territorio se concibe como un agente de transformación social y no únicamente como simple espacio geográfico o soporte funcional para el despliegue de actividades $^{8}$. Se quiebra con ello, definitivamente la imagen de un modelo único y homogéneo de desarrollo (basado en la inversión verticalmente integrada y concentrada en focos, por lo general en el ámbito urbano o próximos a él), dando paso a una discusión más profunda sobre las relaciones entre desarrollo y territorio, e induciendo cambios en la evolución de la economía y la política regional así como en los modelos de desarrollo a nivel local?.

Dentro de este nuevo enfoque, los elementos más relevantes no son tanto los habitualmente considerados dentro de la función de producción, sino otros que se encuentran detrás y que condicionan las posibilidades de acumulación de capital y de conocimiento ${ }^{10}$. Esos nuevos

7 ROMER, P.M.: «The Origins of Endogenous Growth», Journal of Economic Perspectives, 8 (1). 1994, pp. 3-22.

JORDÁN, J., ANTUÑANO, I. y FUENTES, V.: «Desarrollo endógeno y política anticrisis», CIRIEC-España, n. ${ }^{\circ}$ 78, 2013, pp. 245-263.

8 ALBURQUERQUE LLORENS, F.: Desarrollo económico territorial: guía para agentes. Instituto de Desarrollo Regional, Fundación Universitaria, 2001. Sevilla.

9 VÁZQUEZ BARQUERO, A: «El desarrollo local: una estrategia para el nuevo milenio». REVESCO, n. ${ }^{\circ} 68,1999, \mathrm{pp} .15-23$.

10 RODRIGUEZ COHARD, J. C.: «El desarrollo local como nueva estrategia de desarrollo económico y social». En Buendía y García: Cooperativismo y desarrollo local, Editorial Centro de Estudios Ramón Areces, 2003, pp. 1-27. 
factores de desarrollo territorial tienen que ver con el grado de creación y difusión de las innovaciones, la capacidad para promover una organización flexible de la producción, la posibilidad de generar economías de aglomeración y de asociacionismo empresarial, así como la presencia y el fortalecimiento de instituciones comprometidas con el proceso de desarrollo territorial, local o rural.

Con el tiempo, estos incipientes modelos de desarrollo territorial de carácter endógeno y base local, inicialmente centrados en lograr la transformación de la estructura productiva de un territorio o comunidad local, fueron evolucionando hacia otros que tomaban en consideración procesos de desarrollo más integrales y sostenibles, procurando alcanzar mejoras en el bienestar social de la población, fomentando iniciativas empresariales competitivas pero que, a la vez, promoviesen un acceso más equitativo de la población a los recursos y una más justa distribución de la renta generada; y prestando, además, especial atención la preservación del medio ambiente en un horizonte temporal de largo plazo. En resumen, orientados a impulsar el desarrollo económico a través de la generación de empleo productivo y con progresos en la equidad social y la sostenibilidad ambiental.

Los ejes fundamentales de este nuevo enfoque en las estrategias de promoción del desarrollo económico territorial serían: Eficiencia, a través de la búsqueda de mejoras de la productividad y de la competitividad de las empresas; Cohesión social, propiciando un desarrollo económico más equilibrado, que tienda a reducir las desigualdades socioeconómicas entre personas y territorios; Sostenibilidad, con especial atención al objetivo de preservación del medio ambiente y la mejora del nivel y la calidad de vida de las personas desde una perspectiva temporalmente amplia.

De acuerdo con ello, los nuevos modelos de desarrollo territorial desde esta nueva perspectiva contemplan, para el cumplimiento de sus objetivos, una triple dimensión operativa: «integra/», «integrada» e «integradora». Así, el binomio territorio-población pasa a ser concebido como una única categoría conceptual (visión integral), que precisa de todos y cada uno de los recursos presentes en él (visión integrada) y que ha de buscar entre sus finalidades la obtención de efectos sinérgicos (visión integradora) ${ }^{11}$

Actualmente, los modelos de desarrollo endógeno se han generalizado en todos los países, siendo también auspiciados desde las propias

11 CALVO PALOMARES, R.: «La creación de empresas de economía social desde el modelo de desarrollo local». Ponencia en: VIII Seminario Práctico de Economía social. »La economía social, el emprendimiento y el desarrollo territorial». 2011, Valladolid. 
instituciones europeas, como una recomendación de actuación para la generación de riqueza y empleo desde el ámbito regional y local, con particular aplicación en el ámbito de las zonas rurales, pero también en áreas industriales en declive y en ámbitos urbanos económica y socialmente degradados ${ }^{12}$.

En el contexto de la Unión Europea, la política de desarrollo territorial se integra en la Estrategia Europa $2020^{13}$ a través de la denominada "Agenda Territorial de la Unión Europea 2020»(AT2020)14 aprobada en mayo de 2011. En concreto, la AT2020 propone, para el cumplimiento de sus objetivos, la aplicación de un enfoque orientado a los territorios («place-based approach»), basado en la utilización del potencial de desarrollo endógeno de cada lugar como mecanismo para impulsar procesos de cohesión territorial a nivel local, regional y nacional. De acuerdo con ello, se insta al conjunto de la comunidad y, en particular, a los agentes que toman decisiones dentro de cada nivel territorial, a participar de forma activa en el diseño y puesta en marcha de objetivos y mecanismos específicos, a la medida de cada lugar, para mejorar su desarrollo territorial. $Y$, entre sus prioridades, también incluye la actuación integral sobre las zonas rurales de la Unión Europea, de modo que el desarrollo sostenible de estas zonas debería tener en cuenta sus características únicas y sus problemas específicos (ruralidad, despoblación, inaccesibilidad, etc.), tratando de fomentar el espíritu empresarial y de crear unas capacidades locales sólidas en términos de condiciones de vida atractivas y de servicios públicos para los habitantes y las empresas.

En lo referente específicamente al desarrollo territorial en zonas rurales, la actual política de desarrollo rural de la Unión Europea mantiene una identidad diferenciada dentro de la estrategia Europa 2020, aunque sigue operando de la mano y en concordancia con los objetivos de la Política Agraria Común (PAC). Esta política se aplica a través de los Programas de Desarrollo Rural (PDR), nacionales y/o regionales, de siete años de duración, con la financiación del Fondo Europeo Agrícola de Desarrollo Rural (FEADER), aunque cuentan con apoyo finan-

12 COMITÉ DE LAS REGIONES: «Asociaciones entre las autoridades locales y regionales y las organizaciones socioeconómicas: contribución al empleo, al desarrollo local y a la cohesión social» (2002/C 192/13). DOUE 12.08.2002.

13 COMISIÓN EUROPEA: «Europa 2020: Una estrategia para un crecimiento inteligente, sostenible e integrador». Comunicación de la Comisión, de 3 de marzo de 2010, [COM(2010) 2020 final].

14 COMISIÓN EUROPEA: «Agenda Territorial de la Unión Europea 2020. Hacia una Europa integradora, inteligente y sostenible de regiones diversas». Reunión ministerial de Gödöllö, mayo de 2011. 
ciero de otros fondos de la Unión Europea (FEDER, FSE, Fondo de cohesión, etc.). Para el vigente período 2014-2020, los objetivos a largo plazo de la política de desarrollo rural de la Unión Europea son: mejorar la competitividad de la agricultura; garantizar la gestión sostenible de los recursos naturales y la acción por el clima; y lograr un desarrollo territorial más equilibrado de las economías y comunidades rurales, incluyendo la creación y conservación del empleo ${ }^{15}$. En este sentido, la Comisión hace hincapié en la competitividad de la agricultura, promoviendo la innovación, favorecer la correcta gestión de los recursos naturales y apoyar el desarrollo territorial equilibrado mediante el fomento de las iniciativas locales.

En la actualidad, en buena parte como consecuencia de la aplicación de la nueva política de desarrollo rural y de la reforma de la Política Agraria Común (PAC), las economías rurales de la Unión Europea han dejado ya de ser sinónimo de sistemas productivos basados exclusivamente en la agricultura, habiendo experimentado notables procesos de diversificación productiva en aras de la multifuncionalidad del medio rural, en el que apuesta por diversificar las actividades y valorizar los recursos endógenos existentes en esas áreas (naturaleza, paisaje, patrimonio, cultura, etc.) ${ }^{16}$.

$Y$ en este contexto, las entidades de la economía social, particularmente las cooperativas, en cuanto que organizaciones participativas vinculadas, a través de sus socios, a los intereses de la comunidad local y con influencia en sus decisiones, así como fuertes anclajes en el territorio, configuran un modelo empresarial que ha contribuido notablemente al desarrollo económico y social de estas zonas, como así corroboran los resultados de numerosos estudios ${ }^{17}$.

15 REGLAMENTO (UE) n. ${ }^{\circ}$ 103/2013 del Parlamento Europeo y del Consejo, de 17 de diciembre de 2013, relativo a la ayuda al desarrollo rural a través del Fondo Europeo Agrícola de Desarrollo Rural (FEADER) y que deroga el Reglamento (CE) n. ${ }^{\circ}$ 1698/2005 del Consejo.

16 MOYANO ESTRADA, E.: Multifuncionalidad, territorio y desarrollo de las áreas rurales. Ambienta: Revista del Ministerio de Medio Ambiente, n. ${ }^{\circ} 81,2008$, pp. 6-20.

17 BUENDIA MARTINEZ, I.: "Las cooperativas en el marco de las iniciativas públicas de desarrollo rural. Un análisis del caso español». REVESCO, n. ${ }^{\circ} 68,1999$, pp. 75-93.

BEL DURAN, P.: «Las sociedades cooperativas motores del desarrollo territorial», en Juliá, Meliá y Server (dir): Cooperativismo agrario y desarrollo rural, UPV, 2005, pp. 55-84.

COQUE MARTINEZ, J.: Compartir soluciones: Las cooperativas como factor de desarrollo en zonas desfavorecidas, Consejo Económico y Social, 2005, Madrid. 


\section{El modelo cooperativista y la economía social}

El concepto de economía social presenta acepciones diversas que le confieren un carácter esencialmente abierto a la vez que una cierta dosis de ambigüedad. En el ámbito científico, una definición operativa es la que propone el Consejo Económico y Social Europeo (CESE) de conformidad con la asociación científica CIRIEC y que distingue dos subsectores dentro del ámbito de la economía social ${ }^{18}$.

- Subsector de mercado, configurado por empresas con organización democrática (una persona, un voto), con distribución de beneficios no vinculada al capital aportado y cuya principal fuente de recursos la constituye la venta de bienes y/o servicios en el mercado.

- Subsector de no mercado, compuesto por instituciones privadas sin fines de lucro con una actividad sin distribución de beneficios y orientada al servicio de los hogares.

En general, la economía social hace referencia a un conjunto de organizaciones y entidades privadas que, con independencia del sector en el que desarrollen su actividad o de la forma jurídica adoptada (si bien, la cooperativa es la forma más extendida y relevante), nacen como respuesta a alguna carencia o demanda social (empleo, vivienda, calidad de vida, consumo, etc.), persiguiendo una finalidad de servicio a sus socios o a la comunidad, y colaborando de esta forma al bienestar social. Se trata de iniciativas que, en esencia, pretenden cubrir aquellas demandas, problemas y aspiraciones de la población que ni el mercado, en su función de asignación, ni la intervención pública correctora de desigualdades satisfacen o cubren adecuadamente.

Estas entidades se caracterizan por ser organizaciones privadas, de libre adhesión, que actúan en el mercado con plena autonomía de gestión e independencia, dedicándose a producir, asegurar o financiar bienes y servicios, a través de organización de factores productivos que prioriza el elemento humano frente al capital. Así, frente a las empresas donde la distribución del beneficio o la toma de decisiones se realizan en función al capital aportado, en la economía social se prima el

18 COMITÉ ECONÓMICO Y SOCIAL EUROPEO (CESE): La EConomía social en la Unión Europea, Comité Económico y Social Europeo, 2008, Bruselas.

CHAVES R. y MONZÓN, J.L.: Panorama de la investigación en Economía social. Estudios de Economía Aplicada, vol. 26, n. ${ }^{\circ}$ 1, 2008, pp. 29-55. 
trabajo realizado y su toma de decisiones se rige por mecanismos democráticos («un socio, un voto»), con especial consideración de servir a sus miembros y a la comunidad.

En España, la caracterización de las entidades de la economía social en España se recoge en el artículo 2. ${ }^{\circ}$ de la Ley 5/2011, de 5 Marzo, de Economía Social ${ }^{19}$, haciendo referencia al «conjunto de las actividades económicas y empresariales, que en el ámbito privado llevan a cabo aquellas entidades que, de conformidad con los principios recogidos en el artículo 4, persiguen bien el interés colectivo de sus integrantes, bien el interés general económico o social, o ambos». El citado artículo 4 de la Ley, las entidades de la economía social se rigen y actúan por los siguientes principios orientadores:

a) Primacía de las personas y del fin social sobre el capital, que se concreta en gestión autónoma y transparente, democrática y participativa, que lleva a priorizar la toma de decisiones más en función de las personas y sus aportaciones de trabajo y servicios prestados a la entidad o en función del fin social, que en relación a sus aportaciones al capital social.

b) Aplicación de los resultados obtenidos de la actividad económica principalmente en función del trabajo aportado y servicio o actividad realizada por los socios o por sus miembros y, en caso, al fin social objeto de la entidad.

c) Promoción de la solidaridad interna y con la sociedad que favorezca el compromiso con el desarrollo local, la igualdad de oportunidades entre hombres y mujeres, la cohesión social, la inserción de personas en riesgo de exclusión social, la generación de empleo estable y de calidad, la conciliación de la vida personal, familiar y laboral y la sostenibilidad.

d) Independencia respecto de los poderes públicos.

Por su parte, el artículo $5 .^{\circ}$ de la citada Ley identifica las formas jurídicas de las entidades de la economía social en España, incluyendo a las cooperativas, las mutualidades, las fundaciones y las asociaciones que lleven a cabo actividad económica, las sociedades laborales, las empresas de inserción, los centros especiales de empleo, las cofradías de pescadores, las sociedades agrarias de transformación y las entidades singulares creadas por normas específicas que se rijan por

19 LEY 5/2011, de 5 Marzo, de Economía Social. Boletín Oficial del Estado n. ${ }^{\circ} 76$ de 30 de marzo de 2011, pp. 33023-33033. 
los principios establecidos en el artículo anterior ${ }^{20}$. No obstante, dentro del ámbito de la economía social, el modelo cooperativista constituye su representación más genuina y relevante, no sólo por ser una forma empresarial con una larga tradición histórica, sino porque sus valores y principios inspiradores impregnan al conjunto de la economía social21.

La filosofía que subyace en el cooperativismo (y en gran medida en el conjunto de la economía social) parte de unos ciertos valores que rigieron las primeras asociaciones de trabajadores que nacen en respuesta a los abusos del capitalismo industrial del siglo XIX, y entre las que destaca la cooperativa de Rochadle, en 1844, como pionera del movimiento cooperativo moderno.

Aunque la situación actual es bien distinta, puede decirse que los valores básicos de «libertad», «igualdad», «solidaridad» y «participación», entre otros, continúan representado la esencia de estas entidades y han de ser asumidos libremente por todos los socios cooperativistas, y que denotan una clara orientación hacia el valor de la persona, lo que favorece la cohesión interna dentro de la cultura organizacional de las cooperativas.

A través de la cooperación y de la solidaridad entre sus miembros en los procesos, estas entidades se organizan para tener una clara vocación social, con lo que contribuyen a promover valores de igualdad e integración dentro de la sociedad en la que desarrollan su actividad.

En relación con la participación, la especificidad del modelo cooperativo se vertebra en torno a tres ejes: el papel del socio, que no solo aporta capital, sino que actúa como cliente o como trabajador; la gestión democrática, basada en la regla de igualdad de derechos de voto; y el sistema de distribución de beneficios al margen de la aportación de capital de cada socio22. Además, los socios se implican voluntariamente, asumiendo derechos y obligaciones, arriesgando capital y, en ocasiones, el empleo, con lo que el compromiso con el proyecto empresarial es mayor que en otro tipo de organizaciones.

20 La Ley también añade que «podrán formar parte de la economía social aquellas entidades que realicen actividad económica y empresarial, cuyas reglas de funcionamiento respondan a los principios enumerados en el artículo anterior, y que sean incluidas en el catálogo de entidades establecido en el artículo 6 de esta Ley».

21 MONZÓN, J. L.: «La economía social ante los nuevos desafíos», En Fernández Arufe, Gómez García y Román Ortega (Coord.): Estudios de Economía social, Universidad de Valladolid, 2010, pp.21-42.

22 GADEA SOLER, E.: »La función económica de la cooperativa y la necesidad de una legislación adecuada». REVESCO, n. ${ }^{\circ} 108,2012$, pp. 39-58. 
El cooperativismo, desde el valor que representa la solidaridad, también puede prestar un servicio a la sociedad civil, integrando a colectivos con riesgo de exclusión ${ }^{23}$ (a través, por ejemplo, de las Cooperativas denominadas «de iniciativa social») y desarrollando nuevos espacios de empleo y actividad económica, contribuyendo al desarrollo del territorio fundamentalmente en el ámbito local ${ }^{24}$. Y todo ello, asentado en una cultura democrática, donde cada socio tiene iguales derechos de voto (una persona supone un voto), por lo menos en las cooperativas de primer grado.

Las pautas de comportamiento para poner en práctica estos valores se concretan en los denominados «principios cooperativos» que, en su versión más actualizada, fueron enunciados por la Alianza Cooperativa Internacional (ACI), durante el XXXI Congreso, celebrado en 1995 en la ciudad de Manchester. Son los siguientes ${ }^{25}$ :

1. Adhesión voluntaria y abierta. Las cooperativas son organizaciones voluntarias, abiertas a toda persona capaz de usar sus servicios y dispuestas a aceptar las responsabilidades de ser socio, sin discriminación ninguna.

2. Gestión democrática por parte de los socios. Las cooperativas son organizaciones gestionadas democráticamente por los socios, los cuales participan activamente en la fijación de sus políticas y en la toma de decisiones. Los hombres y mujeres elegidos para representar y gestionar las cooperativas son responsables antes los socios. En las cooperativas de primer grado, los asocios tienen iguales derechos de voto y las cooperativas de otros grados están también organizadas de forma democrática.

23 GÓMEZ GARCÍA, J. M. a y ROMÁN ORTEGA, A.: «La economía social en Castilla y León: un sector clave para generar empleo y luchar contra la exclusión social». RUCT, Revista Universitaria de Ciencias del Trabajo, n. ${ }^{\circ}$ 5, 2004, pp. 111-142.

MOZAS MORAL, A. y RODRÍGUEZ COHARD, J.C.: "La economía social: Agente de cambio estructural en el ámbito rural», en Revista de Desarrollo Rural y Cooperativismo Agrario, n. ${ }^{\circ} 4,2000$, pp. 2-7.

24 PÉREZ CARRILLO, B.: «Economía social, cultura emprendedora y desarrollo Local». Ponencia del curso: "La economía social, agente activo del cambio socioeconómico». Escuela de Verano de Economía social de Castilla y León. 2011, Aguilar de Campoo (Palencia).

25 ALIANZA COOPERATIVA INTERNACIONAL (ACI): «La Declaración de la Alianza Cooperativa Internacional sobre la identidad Cooperativa: un informe». Anuario de Estudios Cooperativos. Universidad de Deusto, 1995, pp. 71-97. 
3. Participación económica de los socios. Los socios contribuyen equitativamente al capital social y lo gestionan de forma democrática. Al menos una parte de los activos es, por regla general, propiedad común de la cooperativa. Normalmente reciben una compensación, si la hay, limitada sobre el capital entregado como condición para ser socio. Los socios asignan los excedentes para todos o alguno de los siguientes fines: el desarrollo de la cooperativa; la constitución de reservas, de las cuales, al menos una parte sería indivisible; el beneficio de los socios, en proporción a sus operaciones con la cooperativa; y el apoyo de otras actividades aprobadas por los socios.

4. Autonomía e independencia. Las cooperativas son organizaciones autónomas de autoayuda, gestionadas por sus socios. Si firman acuerdos con otras organizaciones, incluidos los gobiernos, o si consiguen capital de fuentes externas, lo hacen en términos que aseguren el control democrático por sus socios y mantengan su autonomía cooperativa.

5. Educación, formación e información. Las cooperativas proporcionan educación y formación a los socios, a los representantes elegidos, a los directivos y a los empleados para que puedan contribuir de forma eficaz al desarrollo de sus cooperativas. Informan al gran público, especialmente a los jóvenes y líderes de opinión, de la naturaleza y beneficios de la cooperación.

6. Intercooperación (cooperación entre cooperativas). Las cooperativas sirven a sus socios lo más eficazmente posible y también fortalecen el movimiento cooperativo entre ellas, trabajando conjuntamente mediante estructuras locales, nacionales, regionales e internacionales.

7. Interés por la comunidad. Al tiempo que se centran en las necesidades y los deseos de los socios, las cooperativas trabajan para lograr el desarrollo sostenible de sus comunidades, según los criterios aprobados por los socios.

A partir de estos valores y principios, que han de plasmarse en su estructura organizativa, finalidad y funcionamiento, la $\mathrm{ACl}$ ofrece la siguiente definición de cooperativa: «una asociación autónoma de personas que se unen voluntariamente para satisfacer sus necesidades y aspiraciones económicas, sociales y culturales comunes por medio de una empresa de propiedad conjunta gestionada democráticamente».

El elemento que definitorio de la cooperativa es que supone una iniciativa empresarial colectiva que, al margen de la participación ca- 
pitalista de cada socio, persigue la satisfacción de sus necesidades mediante la recuperación de la forma de empresa personalista y de funcionamiento interno democrático.

\section{El cooperativismo y el enfoque del desarrollo territorial udesde abajo»: convergencias y potenciales sinergias}

El nuevo enfoque del desarrollo territorial «desde abajo» se fundamenta en una serie de concepciones y elementos característicos que presentan claros puntos de convergencia con los atributos y cualidades que definen el modelo cooperativista, lo que explicaría su reconocida capacidad para promover e impulsar iniciativas de desarrollo local y rurall $^{26}$, y que son los siguientes:

- El nuevo enfoque del desarrollo territorial se concibe como una estrategia de acción integral sobre el territorio y en su diseño concurren los diferentes ámbitos que determinan el pulso vital del mismo (económico, social, institucional, cultural, histórico, medioambiental, etc.), a la vez que el esfuerzo permanente de todos los actores implicados, públicos y privados, incluidas las propias cooperativas, como parte activa del sector empresarial y de las fuerzas vivas de la comunidad. La implicación estratégica e integral con el territorio es, por tanto, esencial para ambos modelos, siendo el territorio el espacio común en el que se identifican y resuelven los problemas para ambos,

26 MONTERO, A.: «Cooperativismo y desarrollo rural». REVESCO, n. ${ }^{\circ}$ 63, 1997, pp. 63-77.

TOSCANO, F.: «Desarrollo local y Economía social». En Pérez Ramírez, B. y Carrillo Benito, E.: Desarrollo local: Manual de uso, Madrid, ESIC Editorial, 2000, pp. 445-470.

BEL, P. y CABALEIRO, M.J.: "La sociedad cooperativa: fórmula empresarial idónea para el desarrollo rural endógeno y sostenible». Revista Española de Estudios Agrosociales y Pesqueros, n. ${ }^{\circ}$ 194, 2002, pp. 9-26.

COQUE, J.: «El desarrollo local sobre bases cooperativas. Valorización de los recursos locales y creación de redes». En Buendía, I. and García, J.V., coord., 2003, Cooperativismo y desarrollo local, Madrid, C.E. Ramón Areces-Fundación Luis Vives, 2003, pp. 261-299.

MOZAS, A. y BERNAL, E.: «Desarrollo territorial y economía social». CIRIEC-España, n. ${ }^{\circ} 55,2006$, pp. $125-140$.

JUSTE, J.J.: «La Economía social y el desarrollo local. Fundamentos y elementos de conexión». En Fernández, J.E., Gómez, J. M. ${ }^{a}$ y Román, A., coord., 2010, Estudios de Economía social, Valladolid, 2010, pp. 283-324, Universidad de Valladolid. 
tanto en sus dimensiones económica y productiva, como también social.

- En esencia, este nuevo enfoque constituye un modelo descentralizado y participativo del desarrollo territorial, que encuentra un caldo de cultivo especialmente propicio en las sociedades cooperativas, caracterizadas por la democratización en su toma de decisiones. Si de las cooperativas se ha llegado a decir que son escuelas de democracia ${ }^{27}$, el nuevo modelo de desarrollo territorial puede decirse que se origina como una intervención pública en pro de una mejora colectiva28. En ambos casos se busca la implicación de la ciudadanía en el proceso de crecimiento económico y social (participación cívica y democracia, en términos cooperativistas). Se preconizan, en última instancia, una sociedad más plural, participativa, democrática y solidaria. Es, por tanto, la manifestación clara de un compromiso ético con el entorno económico y productivo, pero sobre todo con la sociedad.

- El desarrollo territorial se concibe como un proceso reactivador de la economía y dinamizador de la sociedad local que necesita de la participación del tejido empresarial. La capacidad emprendedora y la orientación hacia la acción son ingredientes que deben estar presentes en el sector productivo en la mayoría de las nuevas iniciativas de desarrollo ${ }^{29}$. El movimiento cooperativo ha venido jugando un importante papel en el sector agrario y en otras áreas afectadas por la lógica de la desinversión y la deslocalización, identificando oportunidades y promoviendo la creación de empresas y grupos cooperativos bajo la filosofía del emprendimiento colectivo. Ello permite a los socios reducir el riesgo de tener que crear su propia empresa a cambio de compartir el beneficio esperado y el poder de decisión.

27 MONZON, J. L.: «Cooperativismo y Economía social: perspectiva histórica», CIRIEC-España, Revista de Economía Pública, Social y Cooperativa, n. ${ }^{\circ} 44,2003$, pp. 9-32.

${ }_{28}$ CHAVES, R.: «La Economía social en España: concepto, agentes y políticas públicas». En Pérez de Uralde, J. M. ${ }^{a}$ (coord.): La Economía social en Iberoamérica. Fundación Iberoamericana de la Economía social, Madrid, 2006, pp. 215-269.

29 GÓMEZ, J.M. ${ }^{a}$ y ROMÁN, A. (2005): «La economía social y su contribución a la promoción del desarrollo local y regional». RUCT, Revista Universitaria de Ciencias del Trabajo, n. ${ }^{\circ} 6,727-753$.

DE PABLO, J. y URIBE, J., 2009, «Emprendimiento de la economía social y desarrollo local: la promoción de incubadoras de empresas de economía social en Andalucía». ClRIEC-España, Revista de Economía Pública, Social y Cooperativa, n. ${ }^{\circ} 64,5-33$. 
El modelo cooperativo también se caracteriza por su proactividad, que define su realidad y relevancia económica y social, así como su lógica de funcionamiento. En el caso de las cooperativas, se persigue el interés del socio (como consumidor y/o trabajador) y el del entorno, siendo éstos los principales destinatarios de sus actuaciones.

- En el marco del enfoque "desde abajo», la estrategia de desarrollo se fundamenta en la movilización de las capacidades y el aprovechamiento eficiente de los recursos del entorno (naturales, humanos, etc.) que configuran su «potencial endógeno». De este modo, se promueven actuaciones que revaloricen los recursos endógenos, generando nuevas oportunidades de mejora del nivel y la calidad de vida de la población ${ }^{30}$. Históricamente, las cooperativas, en tanto que organizaciones empresariales de base y naturaleza social, están ligadas especialmente al entorno, supliendo la escasez de medios financieros con un mejor aprovechamiento de los recursos a su alcance, de acuerdo con los intereses de la comunidad.

- El nuevo modelo de desarrollo territorial promueve la realización de proyectos en los que la población se reconoce y adquiere nuevas competencias, configurando una dinámica local de desarrollo. Pero, para ello, precisa de la participación directa del tejido empresarial local, en especial de las cooperativas ya que, no solo crean empleo, llevan a cabo innovaciones y modernizan la economía, sino que sus beneficios repercuten directamente en el entorno donde se ubican. Además, en el caso del modelo cooperativista, el aprendizaje proveniente de la acción empresarial se ve potenciado por el impulso común que da el proceso de decisión democrática. Su objetivo central, el dar servicio a sus miembros y al entorno que las rodea, favorece el reconocimiento correcto de las necesidades locales y de la mejor forma en que pueden satisfacerse. $Y$ dentro del nuevo enfoque del desarrollo territorial no tiene sentido ninguna actuación emprendida sobre el territorio que no tenga como finalidad última la mejora de la realidad económica y/o social de algún colectivo específico que esté vinculado al mismo.

- El enfoque desarrollo territorial se fundamenta también en la mejora del capital humano existente en la zona, de su forma-

30 STÖHR, W. y TAYLOR, D. (1981): Development from above or below?. Chichester, J.,Wiley and Sons Ltd, Nueva York. 
ción y cualificación, por cuanto resulta crucial para adecuarse a los requerimientos de las empresas locales. Similarmente, dentro del modelo cooperativista, el capital humano también juega un papel esencial para su desarrollo y consolidación. Así, la propensión a cooperar se relaciona, entre otros factores, con la formación y ésta juega un papel clave en el movimiento cooperativista desde sus inicios, ya que forma parte de los principios cooperativos $^{31}$. El principio de educación, formación e información es esencial para la competitividad de las empresas cooperativas, destinando parte de sus recursos a la formación de sus socios y trabajadores, y también al propio fomento del cooperativismo. Se persigue, con ello, mejorar tanto las habilidades técnicas como la cultura empresarial genérica de sus miembros, que repercutirá en una mayor implicación de éstos en la organización de la cooperativa y en el impulso de la innovación frente a los cambios económicos y sociales que se producen en el entorno.

- Por su naturaleza, el proceso de desarrollo territorial «desde abajo» persigue la fijación de la población en el territorio a través del estímulo al crecimiento económico, la creación de puestos de trabajo y la mejora del nivel y la calidad de vida en la comunidad; objetivos particularmente importantes dentro del medio rural. En la medida en que las sociedades cooperativas no se guían única y exclusivamente por el ánimo de lucro, implican la creación de empleo estable y de calidad ${ }^{32}$, así como de una riqueza productiva a menudo orientada también a suplir carencias sociales, anteponiéndose, incluso, a la propia búsqueda de eficiencia en la actividad empresarial. Las cooperativas juegan un papel importante en la mejora del bienestar social, ya que internalizan los intereses de los colectivos sociales del territorio en que se desarrollan, manteniendo fuertes lazos con el tejido económico y social de la zona, y tienden en gran medida a reinvertir los beneficios en el propio territorio. Ello, a su vez, facilitará la generación de otras actividades que favorezcan la permanencia de su población. Desde esta perspectiva, la contribución de

31 SEGUÍ MAS, E. (2007): "Las singularidades del capital humano de las cooperativas como elementos caracterizadores de su capital intelectual», CIRIEC-España, n. ${ }^{\circ}$ 57, 93-115.

32 GÓMEZ, J. M. a ROMÁN, A. y ROJO, C., 2010, «Las dimensiones de la calidad del empleo en la Economía social: análisis de las sociedades laborales y los centros especiales de empleo en Castilla y León». CIRIEC-España, n. ${ }^{\circ}$ 67, 45-74. 
las cooperativas al desarrollo territorial se pone en valor no sólo por la actividad estrictamente empresarial que desempeñan, sino también por su aportación en beneficio de una mayor integración y cohesión social ${ }^{33}$.

- Tanto el nuevo enfoque del desarrollo territorial como el modelo cooperativista presentan una visión estratégica; es decir, de largo plazo. El primero pretende crear las condiciones necesarias para lograr un desarrollo sostenido del territorio, mediante una política de desarrollo de largo alcance y duradera. La filosofía cooperativa, por su parte, propende de forma natural hacia la búsqueda de resultados duraderos en forma de riqueza productiva, de empleos y de bienestar social, y no tanto hacia el logro de beneficios a corto plazo o especulativos. La pervivencia, particularmente en el ámbito agrario, de cooperativas incluso centenarias es prueba evidente del dilatado compromiso temporal que suele caracterizar al modelo cooperativo.

- El nuevo enfoque del desarrollo territorial promueve la especialización productiva en aquellas actividades en las que el área goza de alguna ventaja competitiva, pero también fomenta otras en sectores emergentes como un factor de diversificación necesario. Muchas de estas actividades son nuevos yacimientos de empleo y de marcado carácter local, al estar relacionados con servicios a la comunidad, con la provisión de bienes preferentes o con la preservación del medio ambiente. Tales rasgos entroncan con los principios de participación democrática y de beneficio social al entorno del cooperativismo, lo que le sitúa en una posición favorable para el desarrollo de nuevos nichos de mercado. Además, las cooperativas, en cuanto que basan su actividad en el aprovechamiento de los recursos endógenos de la zona y por su naturaleza mixta económico-social, son entidades especialmente idóneas para el poner en marcha actividades en el ámbito de los nuevos yacimientos de empleo.

- Ambos modelos, el enfoque del desarrollo territorial y el cooperativista, presentan un carácter esencialmente abierto a la colaboración con otros agentes públicos y privados. Aunque en el pasado las autoridades públicas no fueron cruciales en el naci-

33 BEL DURAN, P. y AUSín GÓMEZ, M. (2007): "Contribución de las sociedades cooperativas al desarrollo territorial», REVESCO, n. ${ }^{\circ}$ 92, 2007, pp. 41-71. 
miento de experiencias de desarrollo endógeno, hoy se consideran determinantes para fomentar la consolidación de las existentes, así como para el surgimiento de otras nuevas, mediante una planificación estratégica vinculada a las especificidades de cada zona. Dicho complemento no ha sido ajeno al movimiento cooperativo, mediante normas, estructuras de acompañamiento y ciertas políticas (como el impulso del partenariado entre autoridades locales y cooperativas, con las asociaciones de Agentes de Empleo y Desarrollo Local y con los Grupos de Acción Local) orientadas a la creación de entidades y mejora de su financiación, así como mediante la participación institucional del cooperativismo en los órganos consultivos de elaboración de las políticas y el fomento de la competitividad empresarial con diversas medidas (fiscales, de apoyo financiero y técnico, formativo, etc. $)^{34}$.

- El desarrollo territorial y también el modelo cooperativista se identifican claramente con el objetivo de un desarrollo sostenible $^{35}$. La supervivencia de una economía local depende de la permanencia de la actividad productiva, máxime en zonas rurales. Por ello, la aplicación de criterios en los que la sostenibilidad esté presente, como la preocupación y el respeto por el medio ambiente, son claves. Ello implica la necesidad de considerar su impacto ambiental, así como la integración de las estrategias de desarrollo y de conservación. En el caso del modelo cooperativista, su vinculación con el desarrollo sostenible se hace patente en el principio de «interés por la comunidad», que preconiza que éstas trabajan para conseguir el desarrollo sostenible de sus comunidades, según los criterios aprobados por los socios. Y también por el principio de "adhesión voluntaria y abierta», que garantiza la libertad de su entrada y salida de los socios de la cooperativa, se favorece el impacto intergeneracional de la actividad cooperativa. De este modo, las cooperativas se configuran como unas empresas necesariamente preocupadas por conseguir el desarrollo sostenible de la comunidad en la que realizan su actividad, generando riqueza sostenible sobre su entorno lo-

34 CHAVES, R.: «Las políticas públicas y las cooperativas», Ekonomiaz, n. 79, 2012, pp.168-199.

35 PUENTES POYATOS, R. y VELASCO GÁMEZ, M.M.: «Importancia de las Sociedades Cooperativas como medio para contribuir al desarrollo económico, social y medioambiental, de forma sostenible y responsable», REVESCO, n. ${ }^{\circ}$ 99, 2009, pp. 104-129. 
cal, que a su vez repercutirá sobre la sostenibilidad del entorno a nivel global.

- Las estrategias experiencias de desarrollo "desde abajo» presentan, por naturaleza, una marcada identidad territorial, entendido por éste tanto como el espacio geográfico como el ámbito en el que vive una determinada población. Las cooperativas, por su parte, se identifican estrechamente con el territorio en que operan y suelen constituirse allí donde surge la convicción de poder salir adelante mediante un emprendimiento colectivo. Buscando mejorar el nivel y la calidad de vida, tratarán de aprovechar los recursos a su alcance, vinculando a menudo su actividad a las necesidades locales y tendiendo a reinvertir beneficios en la zona, lo que conjura el riesgo de traslado o cierre selectivo, propio de los procesos de deslocalización habituales en otras formas empresariales. Ello se debe a que su proximidad genera un fuerte arraigo con el territorio y con su comunidad, de modo que sus actuaciones estarán por tanto muy ligadas al territorio y a las personas que lo integran ${ }^{36}$, volcando todos sus esfuerzos dentro de la comunidad a la que pertenecen y convirtiéndose en un instrumento del desarrollo territorial.

A la vista de todas estas consideraciones, tanto el enfoque basado en procesos de desarrollo "desde abajo», endógeno y local, por un lado, como el modelo cooperativista, por otro, constituyen actores trascendentales para el logro del desarrollo económico territorial, particularmente en el entorno rural. En el marco de este espacio común, el interés por la reactivación económica, el aprovechamiento de los recursos autóctonos de la zona, la vinculación del emprendimiento al territorio, la relevancia del capital humano, la fijación de la población y otros aspectos mencionados previamente, representan importantes elementos de convergencia entre ambos. Más aún, cabría pensar que la presencia de los dos modelos tiene la capacidad de generar potenciales efectos sinérgicos positivos a la hora de lograr el desarrollo del medio rural.

Así, en un contexto de creciente globalización y vulnerabilidad económica de los territorios es esencial mejorar la capacidad de movilización del potencial endógeno, la preservación del tejido empresarial local y la adopción colectiva de procesos que persigan la dinamización

36 GARCIA-GUTIÉRREZ FERNANDEZ, C. (1999): "Cooperativismo y desarrollo Local». REVESCO, Revista de Estudios Cooperativos, n. ${ }^{\circ}$ 68, pp. 33-46. 
global del territorio. Dentro de este escenario, el modelo cooperativo presenta, por naturaleza, unas características económicas, organizativas y de funcionamiento especialmente adecuadas para cumplir dicho propósito ${ }^{37}$, posibilitando el surgimiento de potenciales sinergias entre ambos modelos de modo que las actuales estrategias de desarrollo territorial fomentan la labor que, en el plano económico y social, vienen realizando las cooperativas; y éstas, a su vez, proporcionan apoyo e impulso a las medidas de desarrollo económico territorial planteadas a nivel local.

Los potenciales efectos sinérgicos positivos del modelo cooperativo en los procesos de desarrollo territorial rural se derivan, por un lado, de su configuración estructural como una entidad de naturaleza colectiva, lo que proporciona una ventaja competitiva en relación con el resto de opciones empresariales. Esta ventaja obedece a los mecanismos de gestión y de toma de decisiones específicos dentro de la organización cooperativa, resultado de su naturaleza democrática y de su marcada vinculación con el territorio. Este último aspecto es clave dado que su identidad, su papel en el fomento de la cohesión interna, su cultura y su evolución están intrínsecamente ligados al territorio. Estos elementos democratizan el proceso de desarrollo territorial a través del enriquecimiento colectivo 38 y, en última instancia, dotan de mayor autonomía a la comunidad local para definir su propio modelo de desarrollo.

Otro ámbito de posibles sinergias entre el modelo cooperativista y el enfoque basado en la promoción del desarrollo endógeno y local es su capacidad para actuar como agentes dinamizadores del territorio ${ }^{39}$. Ello se debe, por una parte, a que las cooperativas tienen una propensión más alta que otras formas empresariales a reinvertir los beneficios económicos obtenidos en el mismo territorio en el que se localizan, generando también efectos acumulativos en otras actividades, como resultado de su particular lógica a la hora de la distribución de beneficios y excedentes. Y por otra, se debe a su mayor capacidad para promover la generación de «capital social» en el territorio, que

37 MONZÓN, J.L.: «Las cooperativas ante la globalización: magnitudes, actividades y tendencias». Ekonomiaz, n. ${ }^{\circ}$ 79, 2012, pp. 12-29.

PEREZ DE URALDE, J. M. a: "La adecuación de las sociedades cooperativas en las estructuras del desarrollo local». REVESCO, n. ${ }^{\circ}$.68, 1999, pp. 144-147.

38 BUENDÍA MARTÍNEZ, I. y CÔTÉ, A.: «Desarrollo territorial rural y cooperativas: un análisis desde las políticas públicas». Cuadernos de Desarrollo Rural, n. ${ }^{\circ}$ 11(74), 2014, pp. 35-54.

39 DEMOUSTIER, D. (dir): Economie sociale et développement local, Cahiers de I'Economie Sociale, IES - París, 2005, L'Harmattan. 
comprendería el conjunto de conexiones entre personas, a las redes sociales y a las normas de reciprocidad y de confianza que emergen de ellas y que permiten catalizar y afianzar los esfuerzos colectivos, y que es un factor fundamental para propiciar un desarrollo económico sostenido 40 .

El cooperativismo, dado su elevado componente de capital social, aporta ventajas competitivas y estimula iniciativas emprendedoras que favorecen el desarrollo territorial y el crecimiento económico. Por otra parte, la aplicación efectiva del principio de cooperación entre cooperativas fomenta el desarrollo de un entramado empresarial de base cooperativa (por ejemplo, mediante la constitución de cooperativas de segundo grado y de grupos cooperativos). Con ello, se superan las limitaciones que se derivan del menor tamaño y se facilita la aparición de redes empresariales que permiten ampliar su ámbito operativo más allá del mercado local. Todo ello, en beneficio del territorio y su población.

\section{Las cooperativas agrarias y el desarrollo territorial rural en España}

En el contexto del nuevo enfoque de desarrollo territorial rural en España se destaca el papel desempeñado por el cooperativismo agrario. Si bien en el pasado pudo ser habitual que el sector agrario predominara el carácter individualista en la toma de decisiones sobre las actividades productivas, en la actualidad, la actividad agraria moderna muestra un escenario bastante diferente, que vendría caracterizado por un elevado número de asociaciones dentro de este sector ${ }^{41}$. Y ello, porque aunque los agricultores desarrollan actividades agrarias de forma individualizada, en muchos casos, su volumen de producción y capacidad financiera no les permite una respuesta competitiva frente a la acción de empresas más grandes y especializadas. Los pequeños agricultores y ganaderos tienen entonces la alternativa de asociarse entre ellos, constituyendo cooperativas agrarias. De este modo, el cooperativismo ha pasado a ser una seña de identidad del sector agrario (o

40 PUTMAN, R. D.: El declive del capital social. Un estudio internacional sobre sociedades y sentido comunitario, Galaxia Gutenberg, 2003, Barcelona.

41 RAMOS TRUCHERO, G.: «Las cooperativas agrarias en el medio rural: economía y sociedad». Ponencia en: "La economía social en el contexto socioeconómico actual». Escuela de Verano de Economía Social de Castilla y León. 2010, Aguilar de Campoo (Palencia). 
agroalimentario, dada su primordial vinculación a la producción destinada a la alimentación).

Las cooperativas agrarias son, esencialmente, sociedades constituidas por personas que se asocian para la realización de actividades empresariales (comercializar un determinado producto, prestar servicios o adquirir colectivamente ciertos suministros), encaminadas a satisfacer sus necesidades y aspiraciones económicas y societarias, bajo una estructura y un funcionamiento democrático en la toma de decisiones.

Actualmente, las cooperativas agrarias constituyen el movimiento asociativo con mayor presencia dentro de la agricultura y, en general, del sector agroalimentario españo| ${ }^{42}$. Aunque en teoría puede parecer que la naturaleza económica de este asociacionismo es diferente del interés colectivo, en la práctica las cooperativas ejercen un notable liderazgo en la vida económica y social de las comunidades rurales ${ }^{43}$ y, generalmente, actúan como unos agentes propulsores de desarrollo del territorio al aglutinar las iniciativas individuales para el logro de unos objetivos comunes.

Al respecto, un estudio sobre las causas que explican el tamaño del sector cooperativo en el ámbito de la Unión Europea ${ }^{44}$ revela que la existencia de capital social en un entorno es extremadamente importante a la hora de entender el porqué en unos países la fórmula cooperativa prolifera más que en otros. Y es que ese conjunto de redes sociales permite que los individuos adquieran la ventaja de pertenencia a una comunidad, lo que les facilita la adquisición de habilidades y recursos. Las cooperativas incorporan una mayor carga de capital social tanto por su configuración estructural como por el proceso de adscripción de los socios. Por otra parte, la aplicación efectiva del principio de intercooperación entre empresas fortalece el movimiento cooperativo con la aparición de estructuras locales, nacionales, regionales e, internacionales que expanden su ámbito de mercado (internacionalización) y el logro de ventajas competitivas vinculadas a las economías de escala que se derivan de una mayor dimensión empresarial (competitividad). El papel que desempeñan las cooperativas dentro de la eco-

42 JULIÁ, J. F. y MARÍ VIDAL, S.: «Agricultura y desarrollo rural. Contribuciones de las cooperativas agrarias», CIRIEC-España, n. ${ }^{\circ} 41,2002$, pp. 25-52.

43 MOYANO ESTRADA, E.: «El asociacionismo en el sector agroalimentario y su contribución a la generación de capital social», IESA Working Papers Series, 2006, pp. 1-28.

44 CARRASCO, I. y BUENDÍA, I.: «El tamaño del sector cooperativo en la Unión Europea: una explicación desde la teoría del crecimiento económico», CIRIEC-España, n. ${ }^{\circ} 78,2013$, pp. 125-148. 
nomía del sector agrario es, en suma, clave para el sector ya que permite mejorar el poder de negociación y la competitividad de muchos pequeños agricultores y ganaderos en un mercado cada vez más complejo y competitivo.

Por lo que se refiere al modo en que las cooperativas agrarias contribuyen al desarrollo territorial del medio rural en España, cabe señalar diversas vías que se sintetizan a continuación (Ramos, 2010: 10):

- Las cooperativas están en sintonía con el modelo de economía social insertado en la agricultura multifuncional que promueven las instituciones europeas, que no tiene finalidad exclusivamente productiva. El cooperativismo se adapta mejor a las ideas de flexibilidad, especialización y compromiso con lo local que se establecen en las nuevas estrategias de desarrollo territorial y agrarias de la Unión Europea, en las que se apuesta por un mayor protagonismo de la agricultura ecológica y de calidad, por una mejor relación con el medio ambiente ${ }^{45}$ y por la explotación simultánea de nuevos nichos de mercado que, como por ejemplo el caso del turismo rural, que generan mayor valor añadido a los territorios ${ }^{46}$.

- Las cooperativas agrarias son habituales en núcleos rurales, incluso con independencia de su tamaño, y constituyen en muchas ocasiones la principal estructura organizada profesional y estable del medio rural ${ }^{47}$. Actúan, por lo tanto, como un elemento positivo de dinamización económica y permiten una mayor vertebración social del medio rural.

- El cooperativismo agrario, conviene recordar, ha hecho viable el desarrollo y el mantenimiento del sector agrícola en muchos territorios rurales y regiones. Para la agricultura familiar, las cooperativas juegan un papel muy importante, ya que las pequeñas explotaciones agrarias familiares encuentran graves amenazas en el nuevo marco de la globalización y de la apertura de los mercados, a los que no puede hacer frente por sí solas (Juliá y Marí, 2002: 47). Ante esta realidad, las cooperativas constituyen la alternativa viable para que las explotaciones agrarias familiares sean más eficaces a la hora de producir, que puedan adaptarse

45 NOGALES NAHARRO, M. A.: «Desarrollo rural y desarrollo sostenible. La sostenibilidad ética», CIRIEC-España, n. ${ }^{\circ}$ 55, 2006, pp. 7-42.

46 VALOR SALAS, M. T.: "La contribución de las cooperativas al desarrollo rural en Extremadura», comunicación en XIX Reunión Anual ASEPELT, 2005, Badajoz.

47 BAAMONDE, E.: «Las cooperativas agrarias», Agricultura. Revista Agropecuaria, n. ${ }^{\circ}$ Extra 862, 2005, pp. 412-415. 
al desarrollo agroindustrial y para lograr una buena comercialización de todos los productos.

- El entorno cooperativo agrario representa, asimismo, un ámbito en el que pueden ponerse en común las experiencias profesionales y en el que se genera una cierta responsabilidad colectiva en lo relativo al compromiso entre la empresa y el entorno socioeconómico donde se ubica ${ }^{48}$. Esto supone que las cooperativas también pueden contribuir al necesario relevo generacional de las explotaciones familiares y que, de otro modo, muy probablemente habrían desaparecido en mayor medida.

- Tradicionalmente, los núcleos rurales han sido escenarios empresariales que se han visto amenazados por la atomización económica, el aislamiento, la desinformación, el inmovilismo ante la innovación y los cambios tecnológicos, así como por el envejecimiento del capital humano ${ }^{49}$. En este sentido, las cooperativas agrarias han fomentado, bajo muy diferentes puntos de vista, una nueva cultura empresarial en el medio rural, convirtiéndose en unos agentes que incentivan el trabajo colectivo, favorecen la interlocución frente a las instituciones políticas, facilitan la inversión repartiéndola en un mayor número de propietarios, y potencian la capacidad de negociación con respecto a los clientes y, sobretodo, los proveedores.

Pero, además de contribuir a la mejora de las perspectivas productivas de los socios, las cooperativas agrarias también cumplen otras funciones sociales, que se van a extender al medio rural donde se localizan por ser formas empresariales fuertemente enraizadas en el territorio, al contrario de lo que ocurre con otros tipos de explotación productiva desarrolladas bajo un cálculo más exigente entre la inversión realizada y los resultados obtenidos. A través de esas actuaciones, las cooperativas agrarias contribuyen positivamente a fijar población porque no sólo mantienen los empleos de sus socios, sino que generan puestos de trabajo para otras personas dentro de la comunidad en donde se localizan. Así, mientras que en los pueblos es ya cada vez más frecuente que vayan desapareciendo oficios tradicionales y hasta determinados servicios públicos relacionados con las infraestructuras, con la sanidad o con

48 MONTERO GARCIA, A.: «Cooperativismo y desarrollo rural», REVESCO, n. ${ }^{\circ} 63$, 1997, pp. 63-77.

49 CALDENTEY, P.: «Cooperativas agrarias. Las 106 mayores cooperativas agrarias españolas», Agricultura. Revista Agropecuaria, n. ${ }^{\circ} 760,1995$, pp. 940-949. 
la educación, los puestos de trabajo que generan las cooperativas agrarias se siguen manteniendo y, en muchos casos, la cooperativa se convierte en la principal empresa y en el motor de desarrollo endógeno de la propia sociedad agraria (Montero, 1997:72).

Según los datos del Observatorio del Cooperativismo Agroalimentario Español (OSCAE) referidos al año 2012, existían 3.844 Entidades Asociativas Agrarias (EAA) ${ }^{50}$, de las que 3.397 empresas eran cooperativas agrarias, que agrupaban a 1.179 .323 socios. Estas cooperativas proporcionaron empleo directo a cerca de 98.000 trabajadores (fijos y eventuales), en su mayor parte dentro del medio rural (Cuadro 1). Este dato, unido a una facturación total de 25,7 millones de euros en ese año convierte a esta clase de cooperativas en el motor económico y social de las zonas rurales de España.

Por sectores de actividad, las Entidades Asociativas Agrarias suponen el $100 \%$ en la producción de tabaco, el $80 \%$ en la oferta de mosto, el $70 \%$ en la producción de aceite de oliva y vino y el $60 \%$ en la de arroz. También tienen un peso importante, con el $45 \%$ de la producción, en los sectores de cítricos, leche de vaca y de oveja y frutos secos. Y en menor medida (en torno al 35\%) en la producción de aceituna de mesa, de frutas, de carne de ovino y caprino, de cereales, oleaginosas y de algodón.

Pese a que, por efecto de la crisis, el número de empresas agroalimentarias se redujo el $4,4 \%$, las cooperativas agrarias han registraron aumentos en su nivel de empleo y volumen de facturación. Así, entre los años 2007 y 2012, el empleo directo dentro de esta clase de cooperativas aumentó ligeramente por encima del $8 \%$ y la facturación lo hizo en casi el $28 \%$. En el último año, el empleo se había incrementado el $1,4 \%$ y la facturación el $8 \%$ aun cuando el número de cooperativas disminuyó el 0,4\%. Una de las razones de esa evolución positiva se relaciona con el proceso de internacionalización del sector. En el año 2012, el número de cooperativas exportadoras se incrementó un $4 \%$ con respecto al año anterior, hasta alcanzar el $29 \%$ del total de empresas. También aumentó la facturación en los mercados exteriores (el $7 \%$ ), que ya representa el $24 \%$ de la facturación total del sector. En conjunto, las cooperativas agroalimentarias representan el $27 \%$ de total de la facturación exportadora de la industria alimentaria española en ese año.

50 Engloban a las Cooperativas agrarias de 1er. grado y de $2 .^{\circ}$ grado, las Sociedades Agrarias de Transformación (SAT), las Cooperativas de utilización de maquinaria agraria (CUMA) y las Cooperativas de explotación comunitaria de la Tierra (CEC). 


\section{Cuadro 1}

\section{Magnitudes del cooperativismo agroalimentario Español. Año 2012}

\begin{tabular}{|c|c|c|c|c|}
\hline \multirow{2}{*}{$\begin{array}{c}\text { Comunidades } \\
\text { Autónomas }\end{array}$} & \multicolumn{2}{|c|}{ N. ${ }^{\circ}$ cooperativas } & \multirow{2}{*}{$\begin{array}{c}\text { Cifra de negocio } \\
31,5 \%\end{array}$} & \multirow{2}{*}{$\begin{array}{l}\text { Empleo } \\
28,8 \%\end{array}$} \\
\hline & 734 & $21,6 \%$ & & \\
\hline Aragón & 197 & $5,8 \%$ & $7,4 \%$ & $3,2 \%$ \\
\hline Castilla y León & 376 & $11,1 \%$ & $8,9 \%$ & $3,7 \%$ \\
\hline Comunidad Valenciana & 370 & $10,9 \%$ & $8,4 \%$ & $30,8 \%$ \\
\hline Canarias & 78 & $2,3 \%$ & $1,5 \%$ & s.d. \\
\hline Cantabria & 10 & $0,3 \%$ & $0,1 \%$ & $0,1 \%$ \\
\hline Castilla-La Mancha & 414 & $12,2 \%$ & $9,1 \%$ & $6,0 \%$ \\
\hline Cataluña & 324 & $9,5 \%$ & $7,6 \%$ & $5,3 \%$ \\
\hline Extremadura & 290 & $8,5 \%$ & $7,5 \%$ & $4,6 \%$ \\
\hline Galicia & 195 & $5,7 \%$ & $5,9 \%$ & $6,2 \%$ \\
\hline Baleares & 33 & $1,0 \%$ & $0,4 \%$ & $0,3 \%$ \\
\hline La Rioja & 43 & $1,3 \%$ & $0,6 \%$ & s.d. \\
\hline Madrid & 18 & $0,5 \%$ & $0,2 \%$ & $0,2 \%$ \\
\hline Navarra & 98 & $2,9 \%$ & $3,4 \%$ & $2,5 \%$ \\
\hline País Vasco & 65 & $1,9 \%$ & $1,5 \%$ & $0,8 \%$ \\
\hline Principado de Asturias & 22 & $0,6 \%$ & $0,3 \%$ & $0,4 \%$ \\
\hline Región de Murcia & 130 & $3,8 \%$ & $5,7 \%$ & $7,1 \%$ \\
\hline Total Nacional & $\mathrm{CoO}$ & $\begin{array}{l}397 \\
\text { erativas }\end{array}$ & $\begin{array}{l}25.696 \text { Mill.€ } \\
\text { Facturación }\end{array}$ & $\begin{array}{c}97.944 \\
\text { Empleados directos }\end{array}$ \\
\hline
\end{tabular}

Fuente: OSCAE.

En cuanto a su localización geográfica, el 74\% de las cooperativas se concentran únicamente en 6 Comunidades Autónomas (Andalucía, Castilla La-Mancha, Castilla y León, Comunidad Valenciana, Cataluña y Extremadura), que concentran el $73 \%$ de la facturación. Destaca, en este aspecto, el peso relativo del cooperativismo agroalimentario de Andalucía, que aglutina el 21,6\% y el 31,5\% de esas variables, respectivamente.

Finalmente, es también importante resaltar el papel de las cooperativas de segundo grado como que actúan como unas estructuras vertebradoras del sector, al concentrar y gestionar la transformación y comercialización de la producción de un gran número de cooperativas de base. Las 138 entidades de segundo grado representaban, en datos 
para 2012, el $41 \%$ de la facturación total del cooperativismo agroalimentario de España, destacando Coren, Grupo AN, Dcoop (Hojiblanca), Anecoop y Acorex, entre otros.

\section{Conclusiones}

A lo largo de este trabajo se centra en analizar el modelo cooperativo y en poner en valor su papel en el marco del nuevo enfoque de desarrollo territorial "desde abajo». La idea central es que el modelo cooperativista, desarrollado en torno a unos valores y principios de identidad y materializado en la sociedad cooperativa, presenta unas características comunes o convergentes con el nuevo enfoque del desarrollo territorial "desde abajo», de naturaleza endógena y de base local. Por otra parte, este último supone, en esencia, una solución cooperativa del desarrollo económico de un territorio que actúa bajo una perspectiva integral y orientada a mejorar el nivel y la calidad de vida de la población. Los elementos de convergencia existentes entre ambos modelos se relacionan con los siguientes aspectos:

- Implicación estratégica e integral con el territorio, tanto en sus dimensiones económica y productiva, como también social.

- Naturaleza descentralizada y participativa del desarrollo territorial, que se refuerza con la gestión democrática en las sociedades cooperativas.

- Interés por la reactivación económica y la dinamización social, desde la cultura emprendedora y estrategias orientadas a la acción.

- Apuesta por la movilización de las capacidades locales y el aprovechamiento de los recursos endógenos del entorno.

- Generación de una dinámica local de desarrollo con participación directa del tejido empresarial y en la que la población adquiere nuevas competencias.

- Relevancia del capital humano existente en la zona como factor clave para el proceso de desarrollo y el impulso a la innovación.

- Fijación de la población en el territorio a través de la creación de empleo y de la mejora del nivel y la calidad de vida en la zona.

- Visión estratégica, que persigue producir efectos sostenidos a largo plazo, frente a la especulación y la búsqueda de un beneficio rápido y efímero. 
- Especialización en actividades con ventaja competitiva, fomentando la diversificación en nuevos yacimientos de empleo de carácter local.

- Receptividad ante la colaboración de otros agentes, privados y públicos, y a los intereses de la comunidad.

- Identificación explícita con el objetivo de desarrollo sostenible y preservación del entorno.

- Identidad territorial y fuerte arraigo social con la comunidad, como aspectos clave dentro de sus actuaciones.

Estos elementos de convergencia tienen el potencial de generar efectos sinérgicos a la hora de aplicar las estrategias de desarrollo territorial rural, de modo que se refuerza la acción que, en el plano económico y social, lleva a cabo el sector cooperativista; y éste, por su anclaje local y su permeabilidad social, apoya y, en muchos casos, lidera los procesos de desarrollo territorial.

Estos potenciales efectos sinérgicos se derivan, por un lado, de la configuración de las cooperativas como entidades de naturaleza colectiva, lo que les proporciona ventajas competitivas con relación a otras formas empresariales, y que se derivan de sus mecanismos democráticos de gestión y toma de decisiones, así como de su vinculación con el territorio. A ello se añade su capacidad para dinamizar el territorio como consecuencia de su mayor propensión a reinvertir los beneficios en él y también por su lógica a la hora de la distribución de los excedentes. Y por otro, las posibles sinergias generadas por su mayor componente de «capital social», un factor clave para alcanzar un desarrollo económico sostenido. En este aspecto cobra particular relevancia la cultura del emprendimiento colectivo que es inherente al movimiento cooperativo, así como la aplicación del principio de cooperación entre empresas (mediante la constitución de cooperativas de segundo grado y de grupos cooperativos) que permiten ampliar su ámbito operativo más allá del mercado local, en beneficio del territorio y su población.

En el contexto del desarrollo territorial rural en España destaca el papel del cooperativismo agrario, que constituye el movimiento asociativo con mayor presencia dentro del sector agroalimentario español y, en muchas ocasiones, la principal estructura organizada profesional y estable del medio rural.

Actualmente, las cooperativas agrarias ejercen un liderazgo en la vida económica y social de las comunidades rurales, actuando como agentes activos del desarrollo endógeno y local. Su labor favorece la capacidad de negociación y la competitividad del sector agrario en un 
mercado global cada vez más competitivo. Pero, como consecuencia de su anclaje territorial y su permeabilidad a las necesidades de la comunidad local, también promueven la cohesión social de estas zonas, fijando la población y asegurando la pervivencia de muchas explotaciones agrarias.

Si bien las cooperativas agrarias actúan como agentes de dinamización económica y de vertebración social del medio rural, ello no implica que la cooperativa vaya a tener por objetivo primordial el desarrollo territorial rural. Es, ante todo, una empresa y, en este sentido, está obligada a buscar la necesaria eficiencia económica que garantice su supervivencia y el cumplimiento de sus objetivos económicos y sociales. Y ello tiene que ver con la mejora del capital humano, apostar por la innovación y la calidad y promover la cooperación empresarial para superar las limitaciones del tamaño y aprovechar ventajas competitivas. En suma, el modelo cooperativo debe adaptarse a los nuevos retos de la economía globalizada mejorando su capacidad competitiva, pero a la vez tratando de preservar sus señas de identidad. Las administraciones públicas debe ser las encargadas de procurar que las cooperativas se involucren de forma más directa en los proyectos de desarrollo rural, tomando como base el enfoque de desarrollo territorial «desde abajo».

\section{Referencias bibliográficas}

AlbuRQuerque LloRens, F.: Desarrollo económico territorial: guía para agentes. Instituto de Desarrollo Regional, Fundación Universitaria, 2001. Sevilla.

AliAnZa Cooperativa INTERnACIONAL (ACI): «La Declaración de la Alianza Cooperativa Internacional sobre la identidad Cooperativa: un informe». Anuario de Estudios Cooperativos. Universidad de Deusto, 1995, pp. 71-97.

BAAmonde, E.: "Las cooperativas agrarias», Agricultura. Revista Agropecuaria, n. ${ }^{\circ}$ Extra 862, 2005, pp. 412-415.

Bel DuRAN, P.: "Las sociedades cooperativas motores del desarrollo territorial», En Juliá, Meliá y Server (dir): Cooperativismo agrario y desarrollo rural. Universidad Politécnica de Valencia, 2005, pp. 55-84.

Bel Duran, P. y Ausín Gómez, M.: "Contribución de las sociedades cooperativas al desarrollo territorial», REVESCO, Revista de Estudios Cooperativos, n. ${ }^{\circ}$ 92, 2007, pp. 41-71.

Bel, P. y CABAleiro, M.J.: «La sociedad cooperativa: fórmula empresarial idónea para el desarrollo rural endógeno y sostenible». Revista Española de Estudios Agrosociales y Pesqueros, n. ${ }^{\circ}$ 194, 2002, pp. 9-26.

Buendia MARTINEZ, I.: "Las cooperativas en el marco de las iniciativas públicas de desarrollo rural. Un análisis del caso español». REVESCO, Revista de Estudios Cooperativos, n. ${ }^{\circ} 68,1999$, pp. 75-93. 
Buendia Martinez, I y Côté, A.: «Desarrollo territorial rural y cooperativas: un análisis desde las políticas públicas». Cuadernos de Desarrollo Rural, n. ${ }^{\circ} 11(74), 2014$, pp. 35-54.

Buendia Martínez, I. y GarCIA VIDAL, J. (coord.): Cooperativismo y desarrollo local, Madrid, C.E. Ramón Areces-Fundación Luis Vives, 2003, Madrid.

CALDENTEY, P.: "Cooperativas agrarias. Las 106 mayores cooperativas agrarias españolas», Agricultura. Revista Agropecuaria, n. ${ }^{\circ}$ 760, 1995 , pp. 940-949.

Calvo Palomares, R.: «La creación de empresas de economía social desde el modelo de desarrollo local». Ponencia en: VIII Seminario Práctico de Economía social. »La economía social, el emprendimiento y el desarrollo territorial»s. 2011, Valladolid.

CARRASCO, I. y Buendía, I.: «El tamaño del sector cooperativo en la Unión Europea: una explicación desde la teoría del crecimiento económico», CIRIECEspaña, Revista de Economía Pública, Social y Cooperativa, N. ${ }^{\circ}$ 78, 2013, pp.125-148.

ChAVES, R.: «La Economía social en España: concepto, agentes y políticas públicas». En Pérez de Uralde, J.M. ${ }^{a}$ (coord.): La Economía social en Iberoamérica. Fundación Iberoamericana de la Economía social, Madrid, 2006, pp. 215-269.

ChAVES, R.: «Las políticas públicas y las cooperativas», Ekonomiaz, n. ${ }^{\circ} 79$, 2012, pp. 168-199.

Chaves R. y Monzón, J.L.: Panorama de la investigación en Economía social. Estudios de Economía Aplicada, vol. 26, n. ${ }^{\circ}$ 1, 2008, pp. 29-55.

COMISIÓN EUROPEA: «Europa 2020: Una estrategia para un crecimiento inteligente, sostenible e integrador». Comunicación de la Comisión, 3 de marzo de 2010, [COM(2010) 2020 final].

Comisión EUROPEA: "Agenda Territorial de la Unión Europea 2020. Hacia una Europa integradora, inteligente y sostenible de regiones diversas». Reunión ministerial de Gödöllő, mayo de 2011.

COMITÉ DE LAS REGIONES: "Asociaciones entre las autoridades locales y regionales y las organizaciones socioeconómicas: contribución al empleo, al desarrollo local y a la cohesión social» (2002/C 192/13). DOUE 12.08.2002.

Comité ECONÓMICO Y SOCIAL EUROPEO (CESE): La Economía social en la Unión Europea, Comité Económico y Social Europeo, 2008, Bruselas.

Coque Martinez, J.: Compartir soluciones: Las cooperativas como factor de desarrollo en zonas desfavorecidas, Consejo Económico y Social, 2005, Madrid.

Coque Martínez, J.: «El desarrollo local sobre bases cooperativas. Valorización de los recursos locales y creación de redes». En Buendía, I. y García, J.V. (coord.): Cooperativismo y desarrollo local, Madrid, C.E. Ramón ArecesFundación Luis Vives, 2003, pp. 261-299.

De PABlo, J. y URiBE, J., 2009, «Emprendimiento de la economía social y desarrollo local: la promoción de incubadoras de empresas de economía social en Andalucía». CIRIEC-España, Revista de Economía Pública, Social y Cooperativa, n. ${ }^{\circ} 64,5-33$. 
Demoustier, D. (dir): Economie sociale et développement local, Cahiers de I'Economie Sociale, IES - París, 2005, L'Harmattan.

Fernández ARUFe, J.E., Gómez García, J.M. a y Román Ortega, A. (Coord.): Estudios de Economía social, Universidad de Valladolid, 2010, Valladolid.

GADEA SOleR, E.: "La función económica de la cooperativa y la necesidad de una legislación adecuada». REVESCO, Revista de Estudios Cooperativos, n. ${ }^{\circ} 108,2012$, pp. 39-58.

GarCiA-GutiérRez Fernandez, C.: «Cooperativismo y desarrollo Local». REVESCO, Revista de Estudios Cooperativos, n. ${ }^{\circ}$ 68, 1999, pp. 33-46.

Gómez García, J. M. a y Román Ortega, A.: "La economía social en Castilla y León: un sector clave para generar empleo y luchar contra la exclusión social». RUCT, Revista Universitaria de Ciencias del Trabajo, n. ${ }^{\circ}$ 5, 2004, pp. 111-142.

Gómez García, J. M. a y Román Ortega, A.: "La economía social y su contribución a la promoción del desarrollo local y regional». RUCT, Revista Universitaria de Ciencias del Trabajo, 2005, n. ${ }^{\circ}$ 6, pp. 727-753.

Gómez, J. M. ${ }^{a}$, ROMÁn, A. y Rojo, C.: "Las dimensiones de la calidad del empleo en la Economía social: análisis de las sociedades laborales y los centros especiales de empleo en Castilla y León». CIRIEC-España, Revista de Economía Pública, Social y Cooperativa, n. ${ }^{\circ} 67,2010$, pp. 45-74.

JoRDÁn, J., ANTUÑANO, I. y Fuentes, V.: «Desarrollo endógeno y política anticrisis», CIRIEC-España, Revista de Economía Pública, Social y Cooperativa, 78, 2013, pp. 245-263.

JuLIÁ, J. F. y MARI VIDAL, S.: "Agricultura y desarrollo rural. Contribuciones de las cooperativas agrarias», CIRIEC-España, Revista de Economía Pública, Social y Cooperativa, n. ${ }^{\circ} 41,2002$, pp. 25-52.

JuLIÁ, J.F., MeLIÁ, E. y SeRVER, R. (dir): Cooperativismo agrario y desarrollo rural, Universidad Politécnica de Valencia, 2005. Valencia.

Juste, J.J.: «La Economía social y el desarrollo local. Fundamentos y elementos de conexión». En Fernández, J.E., Gómez, J. M. a y Román, A., coord., 2010, Estudios de Economía social, Valladolid, 2010, pp. 283-324, Universidad de Valladolid.

LEY 5/2011, de 5 Marzo, de Economía Social. Boletín Oficial del Estado n. ${ }^{\circ} 76$ de 30 de marzo de 2011, pp. 33023-33033.

Monzon, J. L.: "Cooperativismo y Economía social: perspectiva histórica», ClRIEC-España, Revista de Economía Pública, Social y Cooperativa, n. ${ }^{\circ} 44$, 2003, pp. 9-32.

MonzÓN, J. L.: «La economía social ante los nuevos desafíos», Fernández Arufe, Gómez García y Román Ortega (Coord.): Estudios de Economía social, Universidad de Valladolid, 2010, pp.21-42.

MonzÓN, J. L.: «Las cooperativas ante la globalización: magnitudes, actividades y tendencias». Ekonomiaz, n. ${ }^{\circ} 79,2012$, pp. 12-29.

MonzÓN, J. L. y ChAVES, R.: La economía social en la Unión Europea. Bruselas: Comité Económico y Social Europeo. Comité Económico y Social Europeo, 2012, Bruselas. 
Moyano Estrada, E.: «El asociacionismo en el sector agroalimentario y su contribución a la generación de capital social», IESA Working Papers Series, 2006, pp. 1-28.

MOYANO EstRADA, E.: Multifuncionalidad, territorio y desarrollo de las áreas rurales. Ambienta: Revista del Ministerio de Medio Ambiente, n. ${ }^{\circ} 81,2008$, pp. 6-20.

Mozas Moral, A. y Rodríguez Cohard, J.C.: "La economía social: Agente de cambio estructural en el ámbito rural», en Revista de Desarrollo Rural y Cooperativismo Agrario, núm. 4, 2000, pp. 2-7.

Mozas Moral, A. y Bernal JURAdo, E.: «Desarrollo territorial y economía social». CIRIEC-España, Revista de Economía Pública, Social y Cooperativa, n. ${ }^{\circ} 55,2006$, pp. 125-140.

Nogales NAHARRO, M. A.: "Desarrollo rural y desarrollo sostenible. La sostenibilidad ética», CIRIEC-España, Revista de Economía Pública, Social y Cooperativa, n. ${ }^{\circ}$ 55, 2006, pp. 7-42.

Observatorio Socioeconómico Del Cooperativismo Agroalimentario Español (OSCAE): Macromagnitudes del Cooperativismo agroalimentario español, 2013. Cooperativas Agroalimentarias de España. Madrid.

Perez De Uralde, J. M. «La adecuación de las sociedades cooperativas en las estructuras del desarrollo local». REVESCO, Revista de Estudios Cooperativos, n. ${ }^{\circ} .68,1999$, pp. 144-147.

Pérez Carrillo, B.: «Economía social, cultura emprendedora y desarrollo Local». Ponencia del curso: «La economía social, agente activo del cambio socioeconómico». Escuela de Verano de Economía social de Castilla y León. 2011, Aguilar de Campoo (Palencia).

Puentes Poyatos, R. y Velasco Gámez, M.M.: «Importancia de las Sociedades Cooperativas como medio para contribuir al desarrollo económico, social y medioambiental, de forma sostenible y responsable», REVESCO, Revista de Estudios Cooperativos, n. ${ }^{\circ}$ 99, 2009, pp. 104-129.

PutMAn, R. D.: El declive del capital social. Un estudio internacional sobre sociedades y sentido comunitario, Galaxia Gutenberg, 2003, Barcelona.

RAMOS TRUCHERO, G.: «Las cooperativas agrarias en el medio rural: economía y sociedad». Ponencia del curso: «La economía social en el contexto socioeconómico actual». Escuela de Verano de Economía social de Castilla y León. 2010, Aguilar de Campoo (Palencia).

Reglamento (UE) n. ${ }^{\circ}$ 103/2013 del Parlamento Europeo y del Consejo, de 17 de diciembre de 2013, relativo a la ayuda al desarrollo rural a través del Fondo Europeo Agrícola de Desarrollo Rural (FEADER) y por el que se deroga el Reglamento (CE) n. ${ }^{\circ}$ 1698/2005 del Consejo.

Rodriguez COHARD, J. C.: «El desarrollo local como nueva estrategia de desarrollo económico y social». En Buendía y García: Cooperativismo y desarrollo local, Editorial Centro de Estudios Ramón Areces, 2003, pp. 1-27.

Rodríguez CohaRD, J. C.: «Los procesos de desarrollo local: formas de organización e instrumentos». Ponencia en: // Seminario Práctico de Econo- 
mía social «La economía social y el desarrollo local y regional». 2005. Valladolid.

ROMER, P.M.: «The Origins of Endogenous Growth», Journal of Economic Perspectives, n. 8 (1). 1994, pp. 3-22.

Seguí MAS, E. (2007): «Las singularidades del capital humano de las cooperativas como elementos caracterizadores de su capital intelectual», ClRIEC-España, Revista de Economía Pública, Social y Cooperativa, n. ${ }^{\circ}$ 57, 93-115.

Toscano, F.: «Desarrollo local y Economía social». En Pérez Ramírez, B. y Carrillo Benito, E.: Desarrollo local: Manual de uso, Madrid, ESIC Editorial, 2000, pp. 445-470.

VALOR SALAS, M. T.: «La contribución de las cooperativas al desarrollo rural en Extremadura», comunicación en XIX Reunión Anual ASEPELT, 2005, Badajoz.

VÁzquez Barquero, A: «El desarrollo local: una estrategia para el nuevo milenio». REVESCO, Revista de Estudios Cooperativos, n. ${ }^{\circ}$ 68, 1999, pp.15-23.

VÁzQuez BARQuero, A.: Las nuevas fuerzas del desarrollo, Editorial Antoni Bosch, Barcelona, 2005, 178 pp. 